REGARDS

SUR LEECONOMIE ALLEMANDE

BULLETIN ECONOMIQUE DU CRAC

\section{Regards sur l'économie allemande}

Bulletin économique du CIRAC

$77 \mid 2006$

Varia

\title{
Assurance maladie : bientôt un « Fonds santé » ?
}

Isabelle Bourgeois

\section{OpenEdition}

Journals

Édition électronique

URL : http://journals.openedition.org/rea/802

DOI : $10.4000 /$ rea. 802

ISBN : 978-2-8218-0850-8

ISSN : 1965-0787

Éditeur

CIRAC

Édition imprimée

Date de publication : 1 juillet 2006

Pagination : 37-38

ISSN : 1156-8992

Référence électronique

Isabelle Bourgeois, "Assurance maladie : bientôt un « Fonds santé »? », Regards sur l'économie allemande [En ligne], 77 | juillet 2006, document 1, mis en ligne le 01 juillet 2008, consulté le 15 septembre 2020. URL : http://journals.openedition.org/rea/802

Ce document a été généré automatiquement le 15 septembre 2020.

(C) CIRAC 


\title{
Assurance maladie : bientôt un «Fonds santé »?
}

\author{
Isabelle Bourgeois
}

\section{La réforme projetée cherche à concilier...}

1 Le projet de réforme du système d'assurance maladie légal sera bouclé avant les vacances parlementaires qui débutent le 8 juillet. C'est l'engagement pris par le gouvernement fédéral. Rude tâche, l'enjeu étant de trouver un compromis entre les deux positions inconciliables défendues par chacune des formations de la coalition (voir REA 65/04).

\section{... l'idée d'une « assurance citoyenne »...}

2 Le SPD (et une partie de la Commission Rürup chargée d'élaborer un projet de réforme) prône une "assurance citoyenne » (Bürgerversicherung) : une cotisation obligatoire pour tous, frappant tous les revenus (pas seulement les salaires), et dont le taux est fonction $\mathrm{du}$ montant des revenus. Ce régime supprime la distinction entre assurance maladie privée et régime légal en généralisant ce dernier. Avantage escompté : l'augmentation des recettes des caisses d'assurance permet d'abaisser les cotisations et de réduire ainsi les coûts salariaux annexes. Inconvénient: la transition est délicate pour tous les assurés du régime privé (fonctionnaires, indépendants et revenus supérieurs) qui risquent de se voir spoliés de leurs droits et de leur épargne santé.

\section{... et celle d'une « prime forfait santé »...}

3 L'Union (et une autre partie de la Commission Rürup) prône une " prime forfait santé " (pauschale Gesundheitsprämie) : une cotisation forfaitaire d'un montant identique pour tous les assurés, qu'ils relèvent du régime public ou privé (la distinction est maintenue) et quels que soient leurs revenus. Pour réduire les inégalités, les revenus inférieurs et 
les familles perçoivent une prime compensatoire financée par l'impôt. Avantage escompté : le financement de la protection maladie ne pèse plus sur le facteur travail. Inconvénient : le financement de la prime compensatoire grève les budgets publics.

\section{... grâce à la création d'un « Fonds santé »}

4 Le gouvernement fédéral s'oriente donc vers un compromis; il porte sur le mode de financement du régime légal (Gesetzliche Krankenversicherung, GKV) qui s'effectuerait via un Fonds santé (Gesundheitsfonds) créé à cet effet. Ce Fonds recueillerait les cotisations (salariés et employeurs), ainsi qu'une taxe nouvellement créée, sorte de CSG payée par tous les contribuables. Les recettes ainsi collectées seraient réparties entre les caisses affiliées à la GKV, chacune percevant le même montant forfaitaire par assuré. Ce financement forfaitaire est censé accroître la concurrence entre les caisses, et donc l'efficience du système. Les caisses bonnes gestionnaires pourraient rembourser à leurs assurés une partie des cotisations versées ou leur proposer des prestations supplémentaires. Les mauvaises gestionnaires seraient en droit de demander à leurs assurés le versement d'une prime d'assurance supplémentaire. Au 23 juin, seule l'architecture générale du Gesundheitsfonds négocié entre Union et SPD était connue.

L'architecture du Gesundheitsfonds en projet

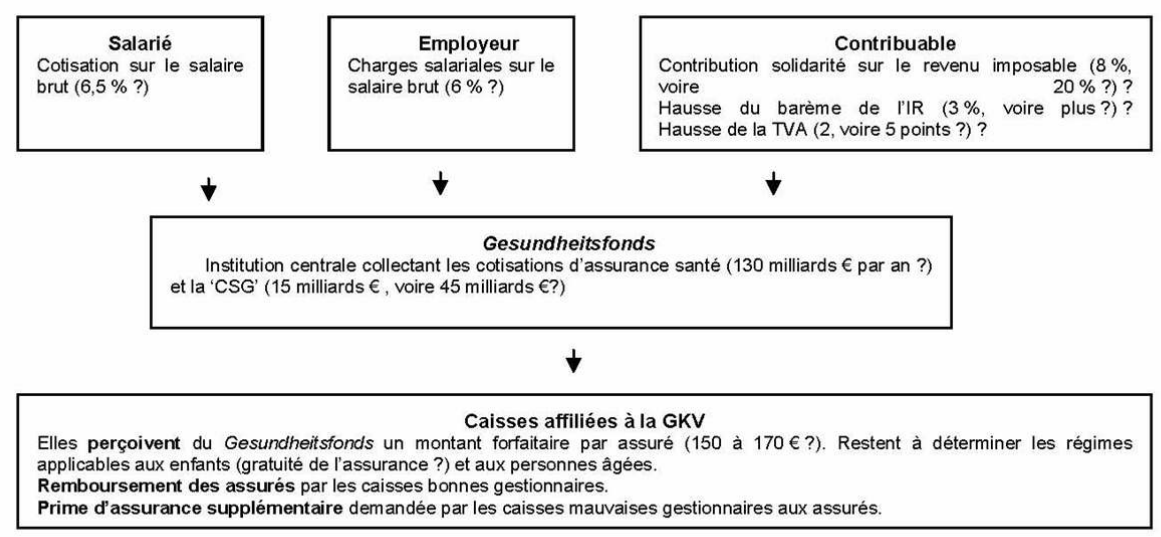

Sources : Süddeutsche Zeitung, 06-06-06 et Frankfurter Allgemeine Zeitung, 10-06-06.

\section{Un projet très critiqué}

5 L'approche de ce Fonds santé cherche à concilier concurrence et redistribution. Cela ne fait pas débat. Mais les commentateurs se demandent si la montagne n'a pas accouché d'une souris. La presse comme les experts sont en effet d'une rare unanimité pour critiquer le projet. Ils invoquent la complexité de sa gestion, mettant en doute jusqu'à sa faisabilité même, et soulignent le fait que ce projet ne résout en rien le problème de fond: la dérive des coûts de l'assurance maladie. Plus fondamentalement, ils incriminent la faible transparence d'une telle entité centralisée qui, de surcroît, ne respecte pas le rôle des partenaires sociaux dans la protection sociale. En outre, le risque est grand que l'administration de ce Fonds, même indirecte, par les pouvoirs 
publics, ne se traduise à moyen terme par une dénaturation de sa mission et qu'il ne soit employé au financement d'autres champs de la protection sociale, notamment la politique familiale.

\section{Plus d'Etat ou plus de marché ?}

6 Il est deux griefs toutefois qui mettent en relief la quadrature du cercle que cherche à résoudre cette tentative de compromis qu'est le Gesundheitsfonds: le premier est que celui-ci «étatise » encore plus l'assurance maladie au lieu de l'ouvrir à la concurrence ; le second porte sur l'institution d'une protection santé «à deux vitesses », donc contraire aux principes de l'Etat social. La ligne de partage dépasse les clivages idéologiques entre les partis.

\section{La Constitution laisse le législateur libre de ses choix}

7 Or ces positions sur la configuration future à donner à la protection sociale sont d'autant plus délicates à concilier que la Loi fondamentale comme la jurisprudence sont muettes sur ce point. Le législateur est libre de donner corps comme il l'entend à l'Etat social, pourvu qu'il en respecte les principes fondateurs. Concrètement, la Loi fondamentale ne lui interdit nullement ni de l'étendre ni de le démanteler. Elle stipule d'une part (art. 20, §1): «La République fédérale d'Allemagne est un Etat fédéral démocratique et social». D'autre part (art.18), elle expose que l'organisation de la vie économique et sociale, ses règles sous-jacentes, doivent respecter "l'ordre constitutionnel libéral et démocratique " (voir REA 52-53/01). Le principe d'Etat social "comprend donc aussi une dimension de liberté", comme le rappelle Hans-Jürgen Papier, président du Tribunal constitutionnel fédéral, dans un entretien accordé au Frankfurter Allgemeine Zeitung (16-06-06). "Les fondements de notre Constitution reposent sur le principe de la responsabilité individuelle. Il est dès lors parfaitement possible, pour préserver durablement l'avenir de l'Etat social, de rééquilibrer la relation entre, d'une part, la solidarité et, de l'autre, la responsabilité individuelle comme la subsidiarité». Au législateur de trouver ce nouvel équilibre. Le Fonds est une tentative. Mais sera-t-elle inscrite dans la durée ? A suivre...

INDEX

Mots-clés : assurance maladie, réforme, santé, système social 